\title{
Thomas: Practical Applications of Agents and Multiagent Systems
}

\author{
Javier Bajo $^{1}$ and Juan M. Corchado ${ }^{2}$ \\ ${ }^{1}$ Pontifical University of Salamanca, Compañía 5, 37002 Salamanca, Spain \\ jbajope@upsa.es \\ ${ }^{2}$ University of Salamanca, Plaza de la Merced S/N, 37008 Salamanca, Spain \\ corchado@usal.es
}

\begin{abstract}
This paper presents a brief summary of the contents of the special session on practical applications held in the framework of IWANN 2009. The special session has been supported by the THOMAS (TIN2006-14630-C03-03) project and aims at presenting the results obtained in the project, as well as at exchanging experience with other researchers in this field.
\end{abstract}

Keywords: Multiagent systems, Agents technology.

\section{Introduction}

Research on Agents and Multi-Agent Systems has matured during the last decade and many effective applications of this technology are now deployed. An international forum to present and discuss the latest scientific developments and their effective applications, to assess the impact of the approach, and to facilitate technology transfer, has become a necessity.

The Special Session on Practical Applications of Agents and Multiagent Systems (http://iwann.usal.es/mas), in the framework of the $10^{\text {th }}$ International WorkConference on Artificial Neural Networks (IWANN 2009) provides a unique opportunity to bring multi-disciplinary experts and practitioners together to exchange their experience in all aspects of Agents and Multi-Agent Systems, especially those concerned with applications, methods, techniques and tools for open multi-agent systems.

The session intends to bring together researchers and developers from industry and academic world to report on the latest scientific and technical advances on the application of multi-agent systems, discuss and debate the major issues, and showcase the latest systems using agent based technology. It is a multidisciplinary discipline that may attract scientist and professionals to IWANN and to provide a different field in which to apply ANN based technology. It promotes a forum for discussion on how agent-based techniques, methods, and tools help system designers to accomplish the mapping between available agent technology and application needs. Other stakeholders should be rewarded with a better understanding of the potential and challenges of the agent-oriented approach. 
This special session has been supported by the THOMAS research project (TIN2006-14630-C03-03), which aim is to advance and contribute methods, techniques and tools for open multiagent systems, principally in the aspects related to organisational structures. THOMAS is a coordinated project in which the University of Salamanca, the Technical University of Valencia and the University of Rey Juan Carlos cooperate to find new solutions in the field of the multiagent systems. This special session provides a framework to disseminate the results obtained in the project and to exchange knowledge with other researchers in the field of the agent technology.

\section{Special Session on Practical Applications of Agents and Multiagent Systems Details}

This volume presents the papers that have been accepted for the 2009 edition. These articles capture the most innovative results and this year's trends: Multi-Agent Systems (MAS) Applications: commerce, health care, industry, internet, etc.; Agent and MAS architectures; Agent development tools; MAS middleware; Agent languages; Engineering issues of MAS; Web services and agents; Agents and grid computing; Real-time multi-agent systems; Agent-based social simulation; Security in MAS; Trust and reputation in MAS; Improving user interfaces and usability with agents; Information recovery with MAS; Knowledge management with MAS; Software Agents in Ubiquitous Computing; Agent technologies for Ambient Intelligence; Software Agents in Industry; Planning and scheduling in MAS; Agent Technologies for Production Systems; Service-Oriented Computing and Agents; Agents for E-learning and education; Mobile computation and mobile Communications. Each paper has been reviewed by three different reviewers, from an international committee composed of 15 members from 7 different countries, and the members of the IWANN 2009 committee. From the 22 submissions received, 17 were selected for full presentation at the conference.

\section{Special Session Acknowledgements}

We would like to thank all the contributing authors, as well as the members of the Program Committee and the Organizing Committee for their hard and highly valuable work. Their work has helped to contribute to the success of this special session. We also would like to thank the IWANN 2009 for giving us the opportunity of organizing the special session, for their help and support. Thanks for your help, the special session on practical applications of agents and multiagent systems wouldn't exist without your contribution.

Acknowledgments. This work has been supported by the MEC TIN2006-14630-C0303 project. 